\title{
Listado y resúmenes de Tesis de Licenciatura de la Facultad de Filosofía y Letras de la UBA
}

\section{Compilado por Débora M. Kligmann}

\section{$2019^{*}$}

» Biodeterioro de cerámica arqueológica de superficie, Valle de Antinaco central, la Rioja. Por Daiana M. Soto

» Tecnología lítica del Holoceno tardío en la estepa fueguina. Actividades de talla y decisiones tecnológicas en Avilés 3.

Por Sabrina A. Labrone

» El cuerpo presentado y representado. Análisis preliminar de figurinas cerámicas antropomorfas del Departamento de Tinogasta (Catamarca, Argentina).

Por Laura S. Vilas

» Usos del cuerpo entre los individuos inhumados en el sitio Chenque I (Parque Nacional Lihué Calel, provincia de La Pampa).

Por Gabriela González

» Patrones de actividad y organización social de los grupos cazadores-recolectores de la cuenca del Lago Salitroso, provincia de Santa Cruz (Argentina) durante el Holoceno tardío: un estudio de las modificaciones osteológicas (artropatías).

Por Milena C. Morlesín

» Osteobiografía de los antiguos habitantes del Valle del Cajón (3600-1300 AP). Variaciones en el uso funcional del cuerpo a partir del análisis de marcadores óseos de actividad.

Por Solange A. V. Raich

» Riesgo ambiental del sitio Cueva de las Manos, Santa Cruz.

Por Carlos E. Zitzke

» El desarrollo de las prácticas y relaciones entre Yaganes y anglicanos en un contexto de negociación, imposición y deconstrucción del poder en el marco de un proyecto de asentamiento misional en la Bahía de Ushuaia a fines del siglo XIX.

Por Axel R. Weissel

" Miradas y valoraciones contenidas en los escritos sobre las pinturas rupestres existentes en Co. Colorado, provincia de Córdoba, entre 1875 y 1975.

Por Schubert Flores Vassella

» Análisis tafonómico y de comportamiento mortuorio del rescate arqueológico de Medanitos Estación XI, departamento de Tinogasta.

Por Julia del Carmen De Stéfano

A continuación se incluyen tres resúmenes de tesis entregados por sus respectivos autores

* Ordenadas por fecha de defensa 